\title{
Effect of aging on airway remodeling and muscarinic receptors in a murine acute asthma model
}

This article was published in the following Dove Press journal:

Clinical Interventions in Aging

17 October 2013

Number of times this article has been viewed

Ji Young Kang

Sook Young Lee

Chin Kook Rhee

Seung Joon Kim

Soon Seog Kwon

Young Kyoon Kim

Department of Internal Medicine, College of Medicine, Catholic

University of Korea, Seoul, Korea
Correspondence: Sook Young Lee Division of Respiratory Medicine, Department of Internal Medicine, Seoul St Mary's Hospital, The Catholic University of Korea, \#505 Banpo-Dong, Seocho-Gu, Seoul, I37-70I, Korea

Tel +82222586061

Fax +8225962158

Email sooklee@catholic.ac.kr
Background and objectives: The influence of aging on the development of asthma has not been studied thoroughly. The aim of this study was to investigate age-related airway responses involving lung histology and expression of muscarinic receptors in a murine model of acute asthma.

Methods: Female BALB/c mice at the ages of 6 weeks and 6, 9, and 12 months were sensitized and challenged with ovalbumin (OVA) for 1 month ( $\mathrm{n}=8-12$ per group). We analyzed inflammatory cells and T-helper (Th) 2 cytokines in bronchoalveolar lavage (BAL) fluid and parameters of airway remodeling and expression of muscarinic receptors in lung tissue.

Results: Among the OVA groups, total cell and eosinophil numbers in BAL fluid were significantly higher in the older (6-, 9-, and 12-month-old) mice than in the young (6-week-old) mice. Interleukin (IL) 4 (IL-4) concentration increased, but IL-5 and IL-13 concentrations showed a decreased tendency, with age. IL-17 concentration tended to increase with age, which did not reach statistical significance. Periodic acid-Schiff (PAS) staining area, peribronchial collagen deposition, and area of $\alpha$-smooth muscle staining were significantly higher in the 6-month older OVA group than in the young OVA group. The expression of the M3 and M2 muscarinic receptors tended to increase and decrease, respectively, with age.

Conclusion: The aged mice showed an active and unique pattern not only on airway inflammation, but also on airway remodeling and expression of the muscarinic receptors during the development of acute asthma compared with the young mice. These findings suggest that the aging process affects the pathogenesis of acute asthma and age-specific approach might be more appropriate for better asthma control in a clinical practice.

Keywords: aging, asthma, airway remodeling, muscarinic receptor

\section{Introduction}

Age-related changes occur throughout the body, including in the respiratory system. Although aging is not a disease, the aging process decreases the functional reserve and increases susceptibility to disease. Morphologic and physiologic abnormalities such as a decline in mucociliary function, dilation of the air spaces, loss of elastic recoil, and evidence of low grade inflammation in the respiratory tract have been observed in the lungs of older humans. ${ }^{1}$ However whether, and to what extent these age-related changes affect the pathogenesis of asthma has not been clarified. Animal models of asthma have produced conflicting data on the age-related changes in airway inflammation. ${ }^{2-5}$ From the clinical aspect, compared with pediatric asthma, adult asthma seems to be more severe and have a low prevalence of atopy, especially in the elderly patients. ${ }^{6,7}$ On the other hand, a large study of pediatric asthma by Illi et $\mathrm{al}^{8}$ found that allergen exposure 
and sensitization in the first 3 years of life predisposes toward the development of chronic bronchial hyper-responsiveness and abnormal lung function by school age. This research suggests that aging may influence the pathogenesis of asthma.

Acetylcholine, a primary parasympathetic neurotransmitter in the airway, affects not only smooth muscle contraction and mucus secretions, but also modulation of inflammation in chronic lung diseases such as asthma and chronic obstructive lung disease (COPD). ${ }^{9-12}$ The primary receptor for acetylcholine in the respiratory system is the muscarinic receptor, which is classified into subtypes $1-5$. The M3 subtype is known to be the most important effector in obstructive lung diseases because it is highly expressed on smooth muscle cells and submucosal glands. ${ }^{13}$ Clinical studies of patients with COPD or severe asthma have shown that tiotropium bromide, a long-acting muscarinic receptor inhibitor with selective affinity for the M3 subtype, reduced the frequency of acute exacerbation, respiratory symptoms, and the progressive decline of pulmonary function. ${ }^{14-17}$ In addition, tiotropium has been shown to attenuate airway inflammation and modulate airway remodeling in a murine model of asthma. ${ }^{11,12}$ These findings suggest that acetylcholine and related muscarinic receptor signaling play a pivotal role in chronic airway diseases. However, the effects and expression of muscarinic receptors in asthma development according to aging remain to be clarified.

The objectives of the present study were to investigate how the aging process affects asthma pathogenesis, as indicated by airway inflammation and structural changes, and whether the expression of muscarinic receptors differs with age in a murine model of asthma.

\section{Materials and methods Sensitization and antigen challenge protocol}

Four groups of female BALB/c mice (Orient, Seongnam, Korea) were used at the ages of 6 weeks and 6, 9, and 12 months. For the older groups, 6-month-old mice were purchased and raised to the age of 12 months in our facilities. Each age group was divided into two groups: a control group $(\mathrm{n}=8)$ and an ovalbumin (OVA) group $(\mathrm{n}=9-12)$. We followed the protocol for inducing acute asthma as described previously. ${ }^{12,18}$ In brief, the mice were immunized on days 0 and 7 by subcutaneous injection of $25 \mu \mathrm{g}$ of OVA grade V; (Sigma-Aldrich, St Louis, MO, USA) adsorbed to $1 \mathrm{mg}$ of aluminum hydroxide (Aldrich, Milwaukee, WI, USA) in $200 \mu \mathrm{L}$ of normal saline. Intranasal OVA challenge $(20 \mathrm{ng} / 50 \mu \mathrm{L}$ in phosphate-buffered saline [PBS]) was administered on days $21,23,25$ and 27 with the animals under isoflurane (Vedco, St Joseph, MO, USA) anesthesia. The age-matched control mice received intranasal challenge of PBS with the same protocol as the OVA-challenged group. Mice were killed 24 hours after the final OVA challenge. All animal experimental protocols were approved by the Animal Subjects Committee of the Catholic University of Korea.

\section{Bronchoalveolar lavage}

A thoracotomy was performed under anesthesia induced by intraperitoneal injection of ketamine and xylocaine. The trachea was exposed and cannulated with silicone tubing attached to a 23-gauge needle on an $800 \mu \mathrm{L}$ tuberculin syringe. The left main bronchus was tied and, following instillation of $1.2 \mathrm{~mL}$ of sterile PBS through the trachea into the right lung, the bronchoalveolar lavage (BAL) fluid was withdrawn. Recovered BAL fluid was cytospun for 7 minutes at $353 \times \mathrm{g}$ at $4^{\circ} \mathrm{C}$, and the supernatant was stored at $-70^{\circ} \mathrm{C}$. The total cell number in the BAL fluid was counted using a hemocytometer. After adjusting the cell number to $1 \times 10^{6} / \mathrm{mL}, 50 \mu \mathrm{L}$ aliquots of BAL fluid were centrifuged onto microscope slides for 5 minutes at $43 \times \mathrm{g}$ and stained with Diff-Quick (Sysmax, Kobe, Japan). The percentages of macrophages, eosinophils, lymphocytes, and neutrophils in the BAL fluid were obtained by counting 500 leukocytes in randomly selected fields of the slide under a light microscope.

\section{Enzyme-linked immunosorbent assay}

The concentrations of cytokines interleukin 4 (IL-4), IL-5, IL-13 in the supernatants of BAL fluids and the concentration of IL-17 in the lung tissue were measured by enzyme-linked immunosorbent assay (ELISA) (R\&D Systems, Minneapolis, MN, USA, and BioSource International, Camarillo, CA, USA, respectively). The assays were performed according to the manufacturers' recommendations.

\section{Histochemistry}

Lung sections were stained with hematoxylin and eosin (H\&E) to identify tissue inflammation with periodic acidSchiff (PAS) stain to identify goblet cell hyperplasia and submucosal gland hypertrophy. Peribronchial inflammation was determined using a semiquantitative score as described by Myou et al. ${ }^{19}$ The severity of the inflammation was graded in five categories: 0 , normal; 1 , few inflammatory cells; 2 , a ring of inflammatory cells 1 cell layer deep; 3 , a ring of inflammatory cells $2-4$ cells deep; 4 , a ring of inflammatory cells of $>4$ cells deep. For the PAS staining, the left lung was removed from each mouse, fixed in $4 \%$ paraformal- 
dehyde, and embedded in paraffin. The paraffin-embedded tissues were sectioned at 5-6 $\mu \mathrm{m}$ and stained with PAS to identify goblet cells in the epithelium. To quantify goblet cell hyperplasia, we used the method described by Padrid et $\mathrm{a}^{20} \mathrm{The}$ pathological changes were evaluated according to the modified five-point scoring system (grade $0-4$ ) and are expressed as the percentage of goblet cells in the epithelium scored as follows: grade 0 (no goblet cells); grade $1,<25 \%$; grade $2,25 \%-50 \%$; grade $3,51 \%-75 \%$; grade $4,>75 \%$. The mean score of goblet cell hyperplasia was calculated for each mouse.

\section{Immunohistochemistry}

Sections were cut at $4 \mu \mathrm{m}$ thickness from lung tissues embedded in paraffin blocks, deparaffinized with xylene, and hydrated in ethanol. The presence of $\alpha$-smooth muscle actin and collagens III was confirmed by immunohistochemistry. For immunohistochemical detection of $\alpha$-smooth muscle actin, the lung sections were incubated overnight at $4^{\circ} \mathrm{C}$ with either a primary monoclonal antibody directed against $\alpha$-smooth muscle actin (Immunohistology kit, IMMH-2; Sigma-Aldrich) or normal mouse serum as a negative control. Immunoreactivity was detected by sequential incubations of the lung sections with a biotinylated secondary antibody, followed by incubation with peroxidase reagent and 3-amino9-ethylcarbazole chromogen. A similar method was used for the immunohistochemical detection of collagens III. The primary monoclonal antibody against mouse collagens III was obtained from Sigma-Aldrich.

\section{Assay to measure hydroxyproline content}

Measurement of total collagen content in the peripheral portions of the lung was based on estimations of hydroxyproline content. A saline solution $(1.5 \mathrm{~mL})$ was added to about $30 \mathrm{mg}$ of tissue sample collected from the peripheral part of the left lower lobe, then the sample was homogenized on ice, and the hydroxyproline content was measured by the spectrophotometrical method.

\section{Measurement of smooth muscle area}

The immunostained area corresponding to $\alpha$-smooth muscle actin in each paraffin-embedded lung was outlined and quantified using a light microscope attached to an image analysis system (BX50; Olympus, Tokyo, Japan). The results are expressed as the area of immunostaining per micrometer length of basement membrane of the bronchioles (150-200 $\mu \mathrm{m}$, internal diameter). At least ten bronchioles were counted in each slide.

\section{Western blot analysis of $\mathrm{M} 2$ and $\mathrm{M} 3$ muscarinic receptors}

Total protein was isolated from lung by homogenization in PRO-PREP ${ }^{\mathrm{TM}}$ protein extraction solution (iNtRON Biotechnology, Seongnam, Gyeonggi-Do, Korea) The lysates were centrifuged at $14,000 \mathrm{~g}$ for 15 minutes at $4^{\circ} \mathrm{C}$ and the supernatants were collected. Protein samples were quantified using the Bradford assay with bovine serum albumin as the standard. The equal amount of sample protein $(50 \mathrm{ug} / \mathrm{mL})$ was then separated by electrophoresis on a $12 \%$ sodium dodecyl sulfate-polyacrylamide gel. The proteins were transferred to a nitrocellulose membrane through a transfer system (X cell II Module). The membranes were blocked with 5\% milk in Trisbuffered saline containing $0.05 \%$ Tween 20 (TBST buffer) for 1 hour at $25^{\circ} \mathrm{C}$, incubated with the primary antibodies, polyclonal rabbit anti-mAChR M2 (H-170, sc-9107; Santa Cruz Biotechnology, Santa Cruz, CA, USA) and mAChR M3 (H-210, sc-9108; Santa Cruz Biotechnology) in 5\% milk in TBST buffer overnight at $4^{\circ} \mathrm{C}$ and then treated with the secondary antibody (anti-rabbit-IgG, horseradish peroxidase [HRP]-linked antibody, Cell Signaling Technology, cat \#7074) for 1 hour at $25^{\circ} \mathrm{C}$. The proteins were detected using an enhanced chemiluminescence system for 3 minutes by exposure to X-ray film (PRO-MG; DaeSung Company, Seoul, Korea).

\section{Statistical analysis}

The significance of differences between groups was assessed by a $t$-test (parametric data) or Mann-Whitney $U$ test (nonparametric data), which was used to analyze PAS point scoring and inflammation scoring statistically. More than two groups were compared by a one-way pairwise analysis of variance (ANOVA) or the nonparametric Kruskal-Wallis test, followed by a post-hoc Dunn's multiple comparison. All results are presented as mean \pm standard error of the mean (SEM). A $P$-value $<0.05$ was considered statistically significant. The Statistical Package for the Social Sciences (SPSS) version 12.0 (IBM, Armonk, NY, USA) was used for all analyses.

\section{Results}

\section{Age-related differences in airway inflammation in the acute asthma model}

To investigate airway inflammation, we analyzed the total cell and differential counts in the BAL fluid (Figure 1). In the control group, the total number of cells and numbers of eosinophils, lymphocytes, and neutrophils in the BAL fluid did not differ between age groups. By contrast, in the OVA 


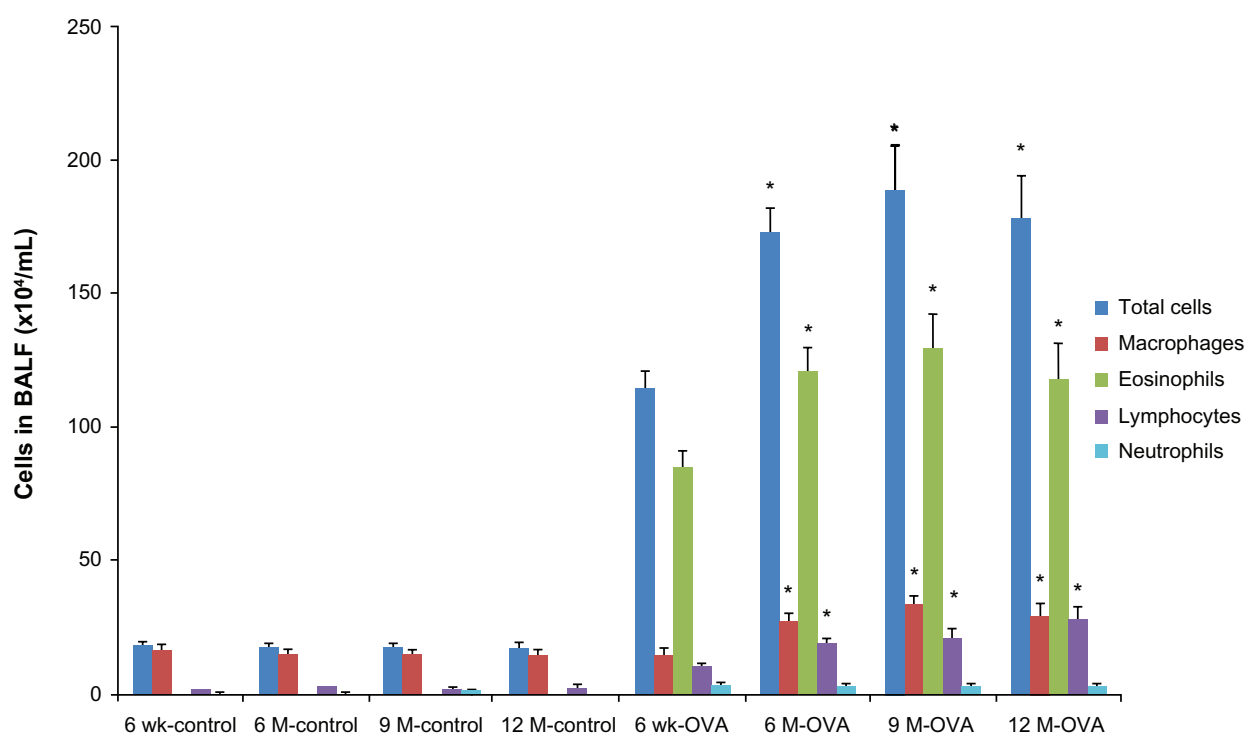

Figure I Pulmonary inflammation according to age in the acute asthma model. Total and differential cell counts in BAL fluid. Notes: Values shown are mean \pm SEM ( $n=8-12$ /group); $* P<0.05$, compared with the 6-week-old OVA group.

Abbreviations: BAL, bronchoalveolar lavage; BALF, bronchoalveolar lavage fluid; OVA, ovalbumin; wk, weeks; M, months; SEM, standard error of the mean.

group, the total number of cells and numbers of eosinophils and lymphocytes in the BAL fluid were significantly higher in the three groups of older mice $(6,9$, and 12 months old) than in the young mice (for total cells, $172.59 \pm 9.05 \times 10^{4} / \mathrm{mL}$, $188.58 \pm 16.91 \times 10^{4} / \mathrm{mL}$, and $178.30 \pm 16.35 \times 10^{4} / \mathrm{mL}$, respectively, versus $114.36 \pm 6.06 \times 10^{4} / \mathrm{mL}, P<0.05$; for eosinophils, $121.39 \pm 7.87 \times 10^{4} / \mathrm{mL}, 128.95 \pm 12.93 \times$ $10^{4} / \mathrm{mL}, 118.71 \pm 12.43 \times 10^{4} / \mathrm{mL}$, respectively, versus $84.78 \pm$ $\left.5.91 \times 10^{4} / \mathrm{mL}, P<0.05\right)$. The number of neutrophils did not differ between age groups in the OVA group. Peribronchial inflammatory cells were significantly higher in 9- and 12-month-old mice than in the young mice of 6 weeks old by the semiquantitative scoring of inflammation ( 9 months old, $3.50 \pm 0.22,12$ months old, $3.33 \pm 0.21$, versus 6 weeks old, $2.50 \pm 0.22, P<0.05$ ) (Figure 2).

\section{Age-related differences in the cytokine profiles in BAL fluid in the acute asthma model}

IL-4 concentration in BAL fluid increased significantly with age in the OVA group (in 6-, 9-, and 12-monthold mice, $86.91 \pm 11.89 \mathrm{pg} / \mathrm{mL}, 127.27 \pm 25.54 \mathrm{pg} / \mathrm{mL}$, $200.18 \pm 43.42 \mathrm{pg} / \mathrm{mL}$, respectively, versus in 6-week-old mice $55.87 \pm 8.02 \mathrm{pg} / \mathrm{mL}, P<0.05)$, but did not change in the control group (Figure 3A). The concentrations of IL-5 and IL-13 were the highest in the young OVA mice (for IL-5, 6 weekold mice, $73.38 \pm 15.10 \mathrm{pg} / \mathrm{mL}$, versus 9- and 12-monthold mice, $36.03 \pm 4.81 \mathrm{pg} / \mathrm{mL}$ and $32.00 \pm 4.88 \mathrm{pg} / \mathrm{mL}$,
$P<0.05$ ), and showed a decreased tendency with age, which had no statistically significant difference between the OVA groups. In the control group, the concentrations of the IL-5 and IL-13 did not differ by age (Figure 3B and C). IL-17, a cytokine involved in severe and neutrophilic asthma, tended to increase with age in the OVA group, even though it was not statistically significant (Figure 3D).

\section{Age-related differences in the parameters of airway remodeling in the acute asthma model}

We analyzed peribronchial fibrosis, goblet cell hyperplasia, and smooth muscle hypertrophy in the lung tissues, all of which are considered important structural changes in asthma. Peribronchial fibrosis was evaluated by the collagen III expression and hydroxyproline content in the lung tissue. The stained area of collagen III was greater in the OVA groups than in their age-matched control groups (Figure 4A). Within the OVA groups, collagen III expression was higher in the three older groups of mice compared with the young mice. In the OVA groups, hydroxyproline content was also higher in the aged mice compared with the young mice (6-, 9-, and 12-month-old mice, $700.61 \pm 49.00 \mathrm{ug} / \mathrm{lung}$, $974.26 \pm 63.79 \mathrm{ug} / \mathrm{lung}, 950.48 \pm 63.45 \mathrm{ug} / \mathrm{lung}$, versus 6-week-old mice, $413.16 \pm 46.68 \mathrm{ug} / \mathrm{lung}, P<0.05$ ) (Figure 4B). Whereas in the control group the hydroxyproline content did not differ between age groups, in all the OVA groups, the content in lung tissue was greater than in 
A $6 \mathrm{~W}$ $6 \mathrm{M}$ $9 \mathrm{M}$ $12 \mathrm{M}$
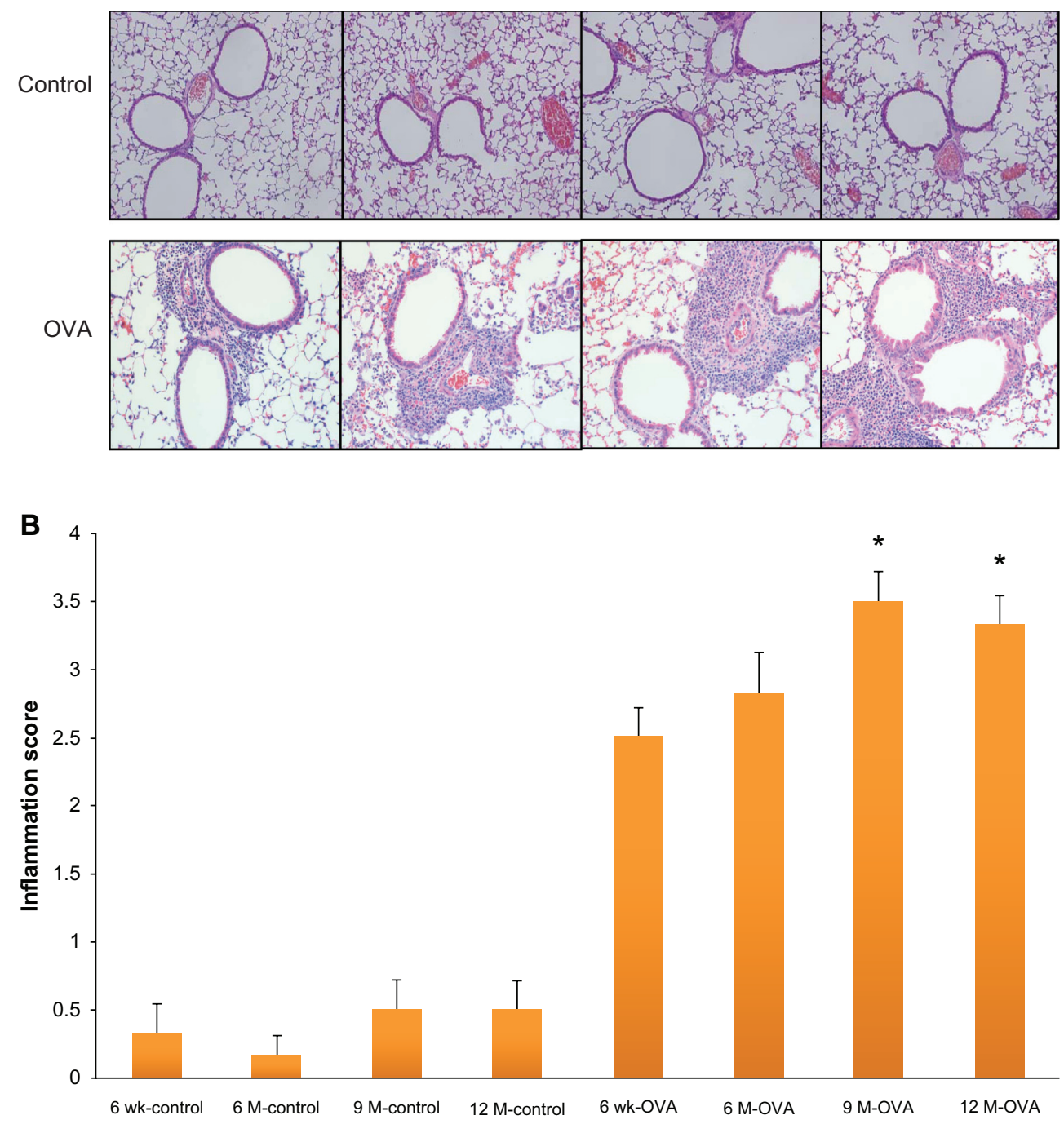

Figure 2 Histologic findings in hematoxylin and eosin staining of the airway (A) and peribronchial inflammation scoring (B) according to age in the acute asthma model. Notes: Values shown are mean \pm SEM ( $n=8-12$ /group); $* P<0.05$, compared with the 6-week-old OVA group.

Abbreviations: W, weeks; wk, weeks; M, months; OVA, ovalbumin; SEM, standard error of the mean.

the respective age-matched control group. PAS scoring of goblet cells showed a trend toward increased grades in the older OVA group than in the young OVA group, although only the 6-month group had a statistically significant difference compared with the young OVA group (6-month-old mice, $3.00 \pm 0.17$, versus 6-week-old mice, $2.20 \pm 0.24$, $P<0.05$ ) (Figure 5). As a measure of smooth muscle hyperplasia, the area immunostained for peribronchial $\alpha$-smooth muscle actin was significantly greater in the 6-month OVA mice than in the young OVA mice (6-month-old mice, $1,835.58 \pm 100.62 \mu \mathrm{m}^{2}$, versus 6-week-old mice, 1,555.53 $\left.\pm 101.39 \mu \mathrm{m}^{2}, P<0.01\right)$. The rest old OVA mice groups yielded a trend of a larger area than the young OVA group, even though it had no a statistically significant difference.
By contrast, the smooth muscle area did not change with age in the control group (Figure 6).

\section{Age-related changes in the expression of muscarinic receptors in the acute asthma model}

Compared with the control groups, the age-matched OVA groups showed a higher expression level of the M3 subtype of muscarinic receptor and a lower expression level of the M2 subtype. The expression of M3 tended to increase with age and was highest in the oldest group, whereas the pattern of M2 expression was the reverse, although these findings did not have a statistical significance except for M3 expression in the 9-month-old OVA group (9-month-old OVA mice, 
A

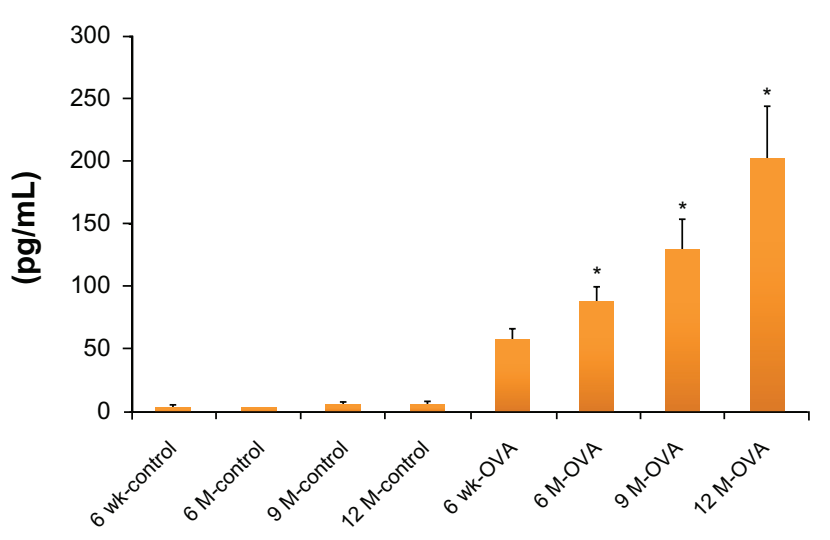

C

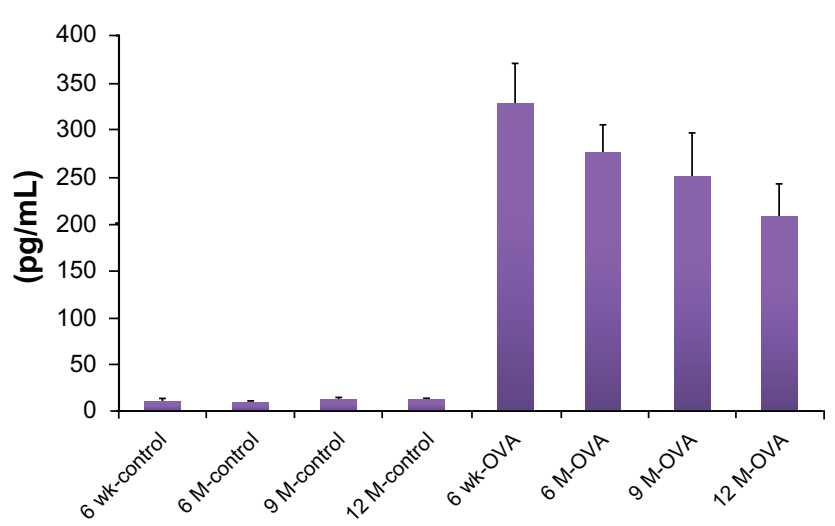

B

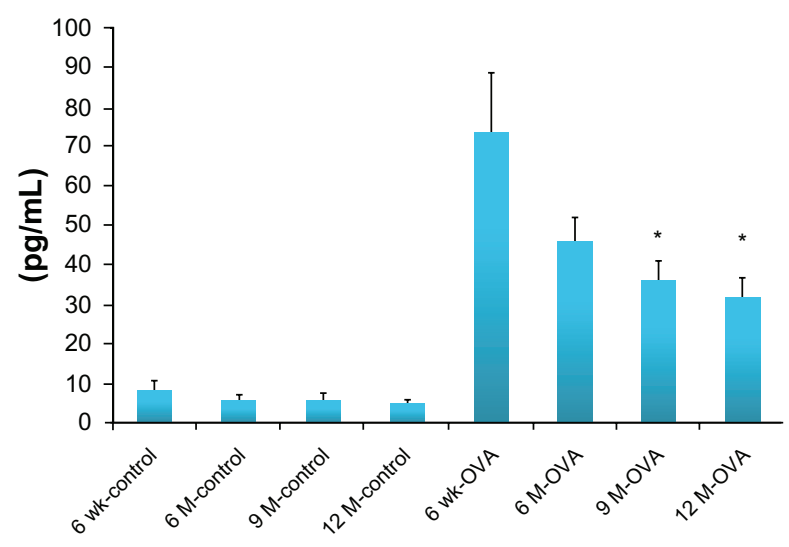

D

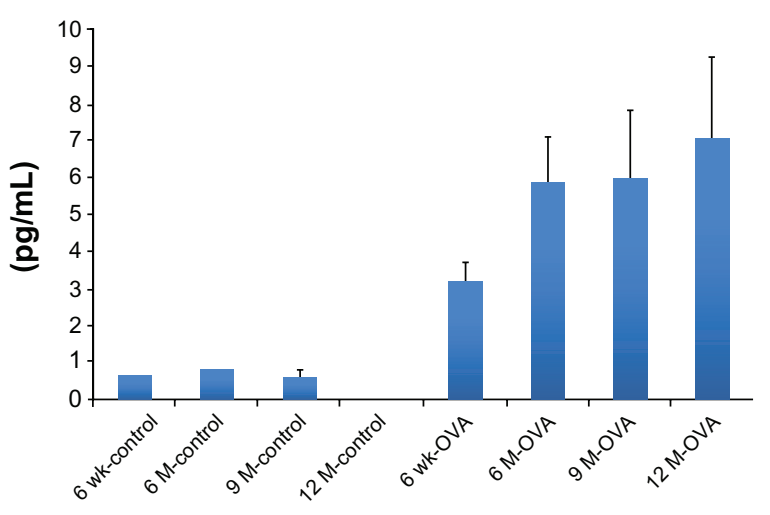

Figure 3 Concentrations of Th2 cytokines (IL-4, A; IL-5, B; IL- I3, C) in BAL fluid and IL-I7 (D) in lung tissue according to age in the acute asthma model. Notes: Values shown are mean \pm SEM ( $n=8-12$ /group); $* P<0.05$, compared with the 6-week-old OVA group.

Abbreviations: IL, interleukin; wk, weeks; M, months; OVA, ovalbumin; BAL, bronchoalveolar lavage; SEM, standard error of the mean.

$60.00 \% \pm 4.5 \%$, versus 6 -week-old OVA mice $37.3 \pm 4.4$ $P<0.05)$. These patterns were similar in both the OVA and control groups (Figure 7).

\section{Discussion}

The current study demonstrates that pulmonary inflammation and structural changes in the airway during development of acute asthma differed between young and older mice. Aged mice showed increased inflammatory cells and IL-4 in BALF and more accentuated pattern of airway remodeling in lung tissue, compared with young mice. Moreover, expression of the main subtypes of muscarinic receptor, M2 and M3, also had some differences by age; in particular, the M3 subtype tended to increase with age in both the OVA and the control groups, although 9-month-old OVA group showed a significant difference, compared with the young OVA group.

Asthma is a chronic inflammatory disease in the airway, and inflammation by itself is thought to be a pivotal factor in asthma development and progression. However, the effects of the aging process on inflammation associated with asthma have not been clarified. Some previous studies have reported that older antigen-sensitized and -challenged animals have a lower total cell count and eosinophils percentage in BAL fluid, and suppressed Th2 cytokines compared with young mice. $^{2-4}$ However, recent data has shown that older OVA mice display greater inflammation compared with young 6-week-old mice. ${ }^{5,21}$ The latter studies also demonstrated unique patterns of changes in the concentrations of individual cytokines with age. In our murine asthma model, we also found higher total cell, eosinophil, and lymphocyte count in BAL fluid in the 6-, 9-, and 12-month-old OVA groups compared with the young OVA group, suggesting that allergic immune response after OVA sensitization and challenge seemed to be greater in the older mice.

We also found age-related differences in Th2 cytokines. IL-4 concentration was significantly higher in older OVA mice than in young OVA mice, and IL-5 and IL-13 concentrations were lower in older OVA mice than in young 

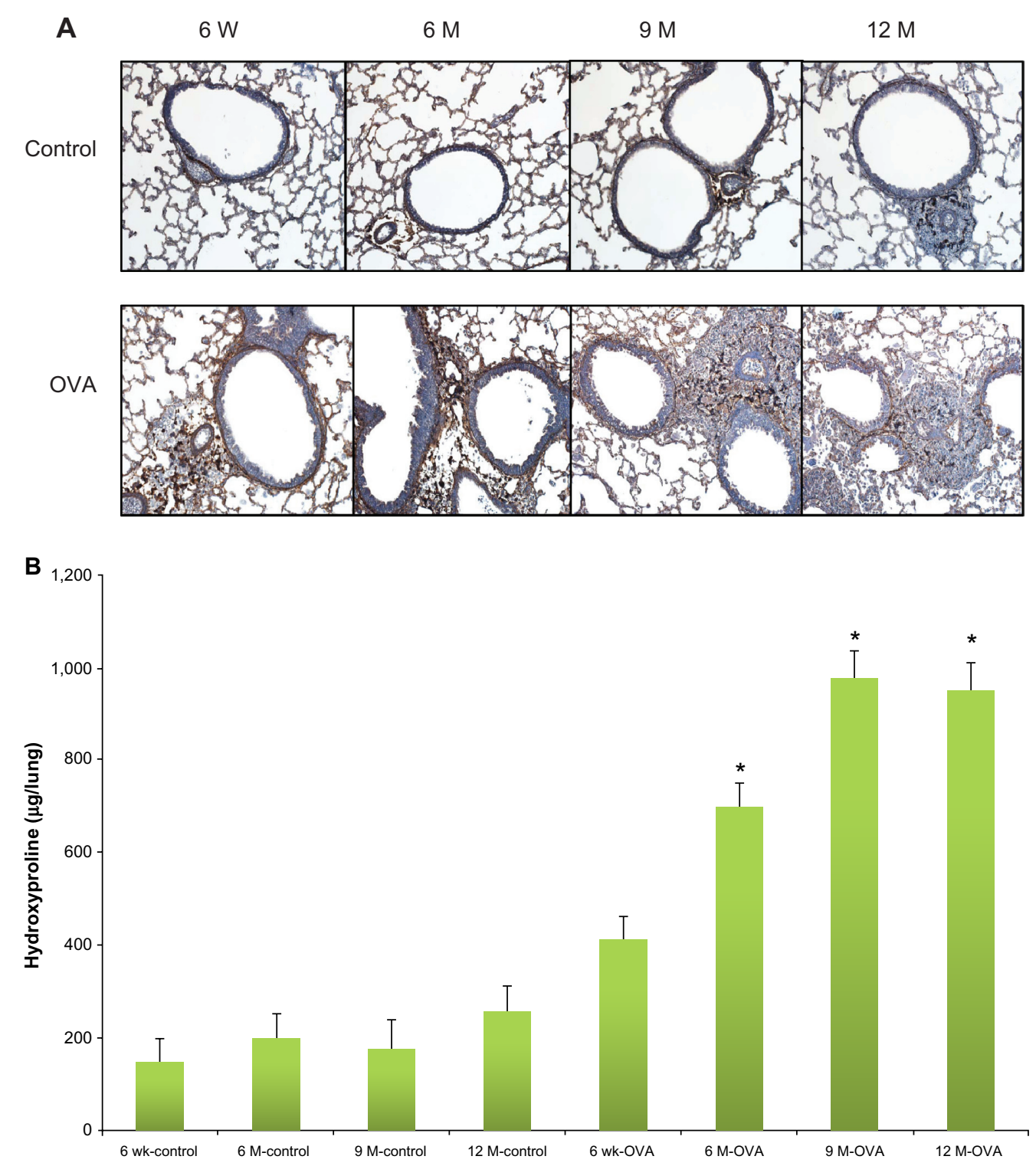

Figure 4 Collagen expression in lung according to age in the acute asthma model. Representative photomicrographs of lung sections stained for collagen III (A) (original magnification $\times 200$ ) and hydroxyproline concentration in lung tissue $(\mathbf{B})$.

Notes: Values shown are mean \pm SEM $(n=8-12 /$ group); $* P<0.05$, compared with the 6-week-old OVA group.

Abbreviations: W, weeks; wk, weeks; M, months; OVA, ovalbumin; SEM, standard error of the mean.

OVA mice. These results differ from those reported in the abovementioned studies. ${ }^{5,21}$ Taken together, it is at least speculated that the profile of Th2 cytokines in a murine asthma model have a distinct pattern depending on age. In the current study, the level of IL-5 in BAL fluid was not positively correlated with eosinophils in BAL fluid. It is speculated that besides IL-5, IL-3 and granulocyte macrophage colony-stimulating factor (GM-CSF), as growth and maturation factors for eosinophils, or eotaxin, as a chemokine to regulate eosinophil trafficking into the airway, might contribute to eosinophilia in old OVA mice groups. ${ }^{22,23}$ Recent research supports the idea that IL-17 is involved in severe asthma ${ }^{24,25}$ and that late-onset asthma has more severe symptoms than does childhood asthma. Silverpil and Lindén ${ }^{26}$ described that although IL-17 can have distinct functions during different conditions in the airways, one thing for certain is that the concentration of IL-17 is higher in asthmatic patients compared with health volunteers, therefore, clearly, there may be an important role for IL-17 in asthma pathogenesis. We measured IL-17 concentration in the lung tissue in older OVA mice for the first time. Although the level of the cytokine did not show a significant differences between the various OVA groups, a higher IL-17 level was found in older OVA mice compared with young OVA mice. By contrast, Alvarez-Rodriguez et $\mathrm{al}^{27}$ showed that in health subjects, age correlated 
A

$6 \mathrm{~W}$

$6 \mathrm{M}$

$9 \mathrm{M}$

$12 \mathrm{M}$
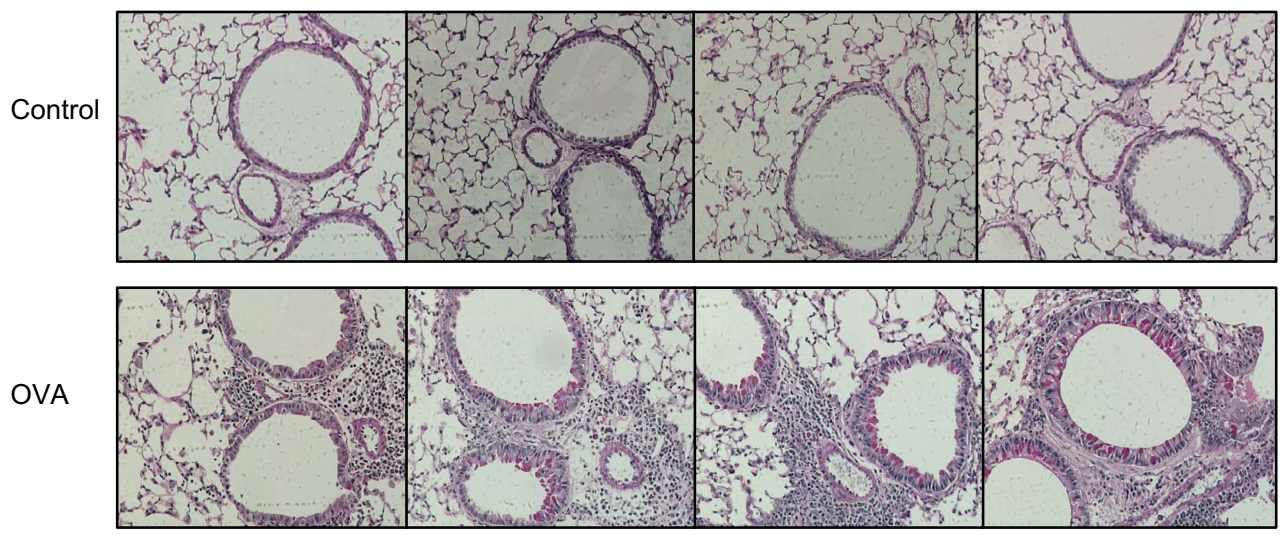

B

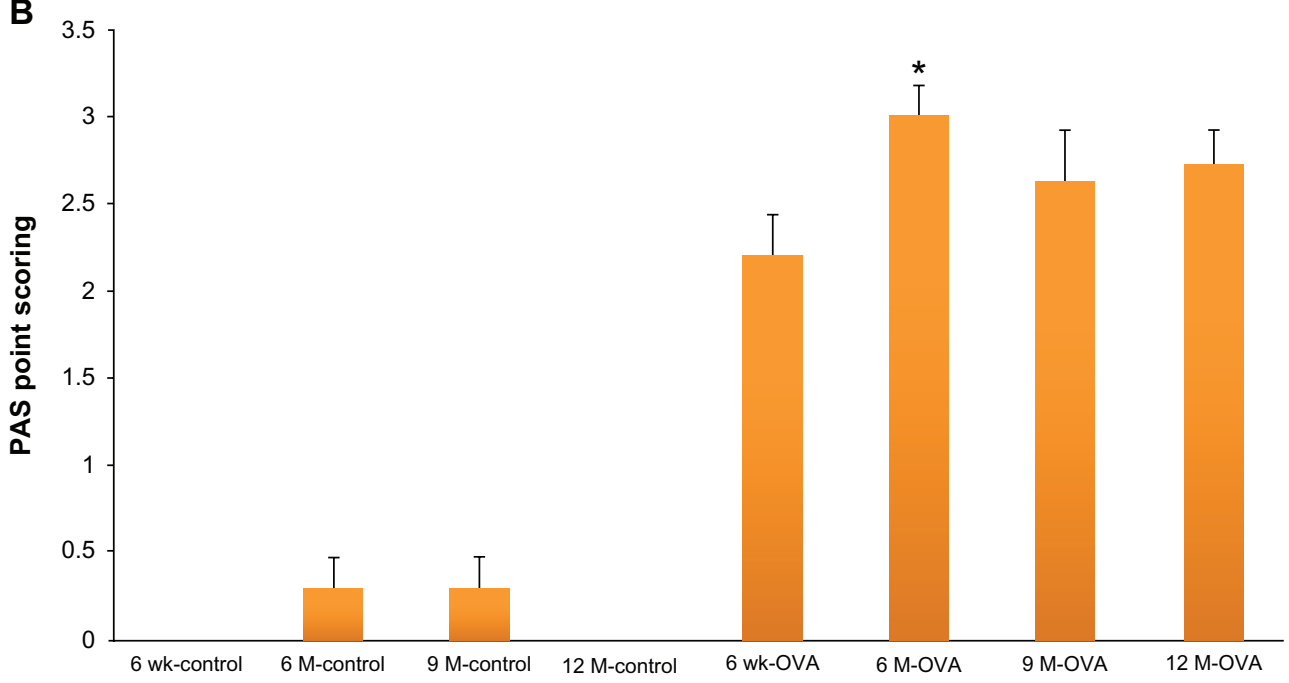

Figure 5 Goblet cell hyperplasia in lung tissue according to age in the acute asthma model. Representative photomicrographs of PAS stained lung sections (A). Quantification of the PAS-stained area by point scoring (B).

Notes: Values shown are mean \pm SEM ( $n=8$-12/group); $* P<0.05$, compared with the 6-week-old OVA group.

Abbreviations: W, weeks; wk, weeks; M, months; OVA, ovalbumin; PAS, periodic acid-Schiff; SEM, standard error of the mean.

negatively with the circulating IL-17 concentration. The role of IL-17 in asthma at different ages should be clarified in further research.

In asthma, particularly in chronic asthma, airway remodeling occurs frequently as peribronchial fibrosis, goblet cell hyperplasia, and smooth muscle thickening. ${ }^{28}$ These structural alterations can cause fixed airway obstruction and ultimately unresponsiveness to asthma treatment. ${ }^{29}$ Busse et $\mathrm{al}^{5}$ reported that MUC-5AC expression and numbers of $\mathrm{PAS}^{+}$-staining bronchial epithelial cells were significantly higher in older OVA mice than in young OVA mice, showing that histologic changes such as mucus cell hyperplasia in asthma occurred to a greater degree in older mice. In the present study, we confirmed more comprehensively the relationship between age and indicators of airway remodeling. In the 6-month-old OVA group, hydroxyproline content, PAS staining, and smooth muscle thickness were significantly greater than in the young OVA group. Although it did not reach statistical significance, the other old OVA mice aged 9- and 12-months also showed a higher tendency of the levels of indicators than the young OVA mice. Intriguingly, the control group showed little effect of age on these parameters. These results suggest the possibility that adult asthma could be more severe and persistent than pediatric asthma due to more aggravated structural alterations of the airway even in acute stages of asthma.

Recent evidence supports the idea that the cholinergic system, including muscarinic receptors, plays a larger role in pulmonary inflammation and airway remodeling in asthma than previously thought. ${ }^{30,31}$ In particular, Grainge et al ${ }^{32}$ reported that with allergen and methacholine administration to asthma patients, bronchoconstriction without inflammation 
A

$6 \mathrm{~W}$

$6 \mathrm{M}$

$9 \mathrm{M}$

$12 \mathrm{M}$
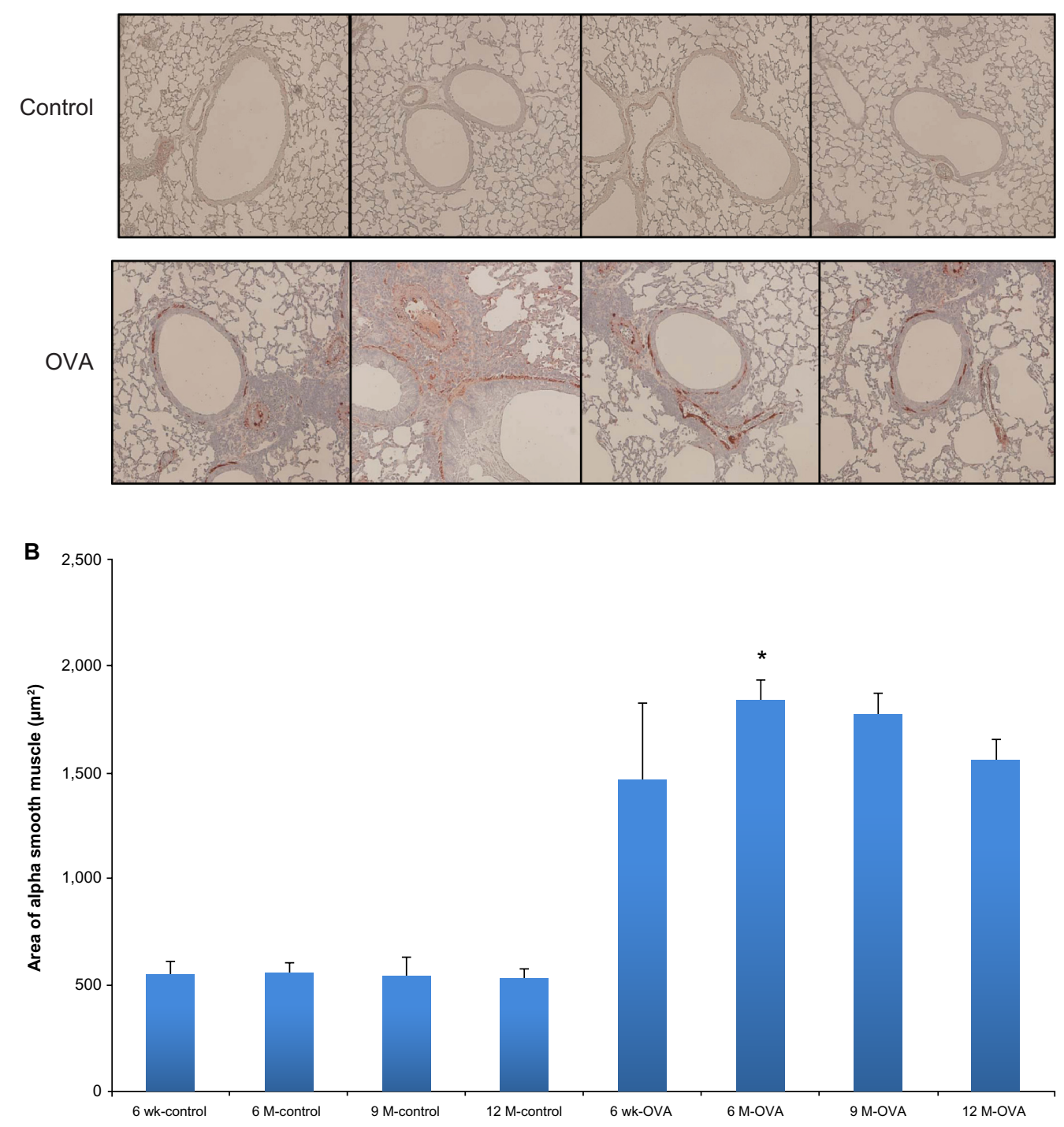

Figure 6 Airway smooth muscle hyperplasia according to age in the acute asthma model. Representative photomicrographs of the area of smooth muscle-stained lung sections (A) (original magnification $\times 200$ ) and smooth muscle areas of immunostaining per micrometer length of basement membrane of the bronchioles, as assessed using an image analyzer (B).

Notes: Values shown are mean \pm SEM $(n=8-12 /$ group); $* P<0.01$, compared with the 6-week-old OVA group.

Abbreviations: W, weeks; wk, weeks; M, months; OVA, ovalbumin; SEM, standard error of the mean.

can induce airway remodeling, as shown by subepithelial collagen deposition and mucous glands hyperplasia. However, there is little research on whether the expression of muscarinic receptors changes with age in asthma. Lee et $\mathrm{a}^{33}$ observed that airway smooth muscle is more sensitive to acetylcholine in vivo and in vitro in young rats than in older rats, possibly because of greater expression of M2 and M3 muscarinic receptors in smooth muscle in young rats. By contrast, the present study showed an increased expression of M3 subtype and a decreased expression of M2 subtype in the lung tissue from older OVA mice compared with young OVA mice, although only M3 expression in the 9-month-old OVA group had a statistical significance. This contradictory finding might reflect the use of different ages and animals, the type of asthma model, and variables measured.

There are some limitations to our study. We used 6 to 12 -month-old $\mathrm{BALB} / \mathrm{c}$ mice as the older group. The lifespan of these mice is 24 months, and our model may not completely reflect asthma in elderly humans. However, the main aim of this study was to investigate whether and to what extent the development of asthma differs with age. In addition, we did not perform invasive measurements or double-chamber plethysmography to evaluate airway hyperresponsiveness and to clarify how these measures change with age. Further research to assess such measurements is needed to investigate the influence of the above peculiar 

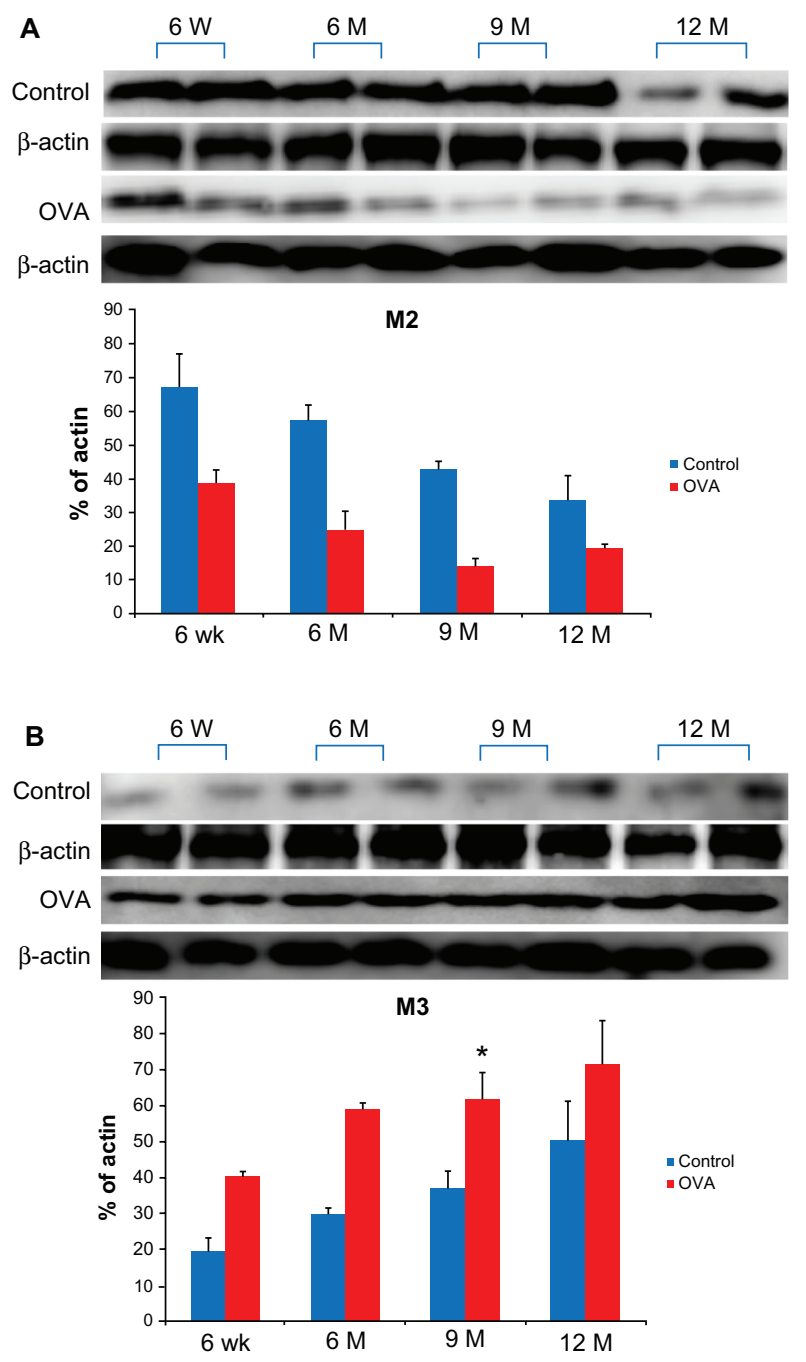

Figure 7 Expression of muscarinic receptors subtype (M2, A; M3, B) in lung tissue relative to $\beta$-actin detected by western blotting with rabbit polyclonal antibodies specific for $\mathrm{M} 2$ and $\mathrm{M} 3$ according to age in the acute asthma model.

Notes: Values shown are mean \pm SEM $(n=8-12 /$ group); $* P<0.05$, compared with the 6-week-old OVA group.

Abbreviations: W, weeks; wk, weeks; M, months; OVA, ovalbumin; SEM, standard error of the mean.

changes in aged asthma on lung function. Finally, we did not take the molecular approach towards aging and smooth muscle contractility. Considering that airway smooth muscle cell in asthma has phenotype plasticity ${ }^{34}$ and extracellular matrix such as collagen and related advanced glycosylation end products, and elastin and elastase-type endopeptidases by produced smooth muscle cell are increased by aging ${ }^{35}$, it seems intriguing to verify the correlation between age and smooth muscle contractile phenotype.

\section{Conclusion}

The current study demonstrated that the aged mice showed an active and unique pattern not only on airway inflammation, but also on airway remodeling and on expression of the muscarinic receptors during the development of acute asthma compared with the young mice. These findings suggest that the aging process affects the pathogenesis of acute asthma and in particular, may be related to disease severity in older murine asthma model more than 6 month-old.

\section{Acknowledgement}

This work was supported by the Korean Association of Internal Medicine Research Grant in 2012.

\section{Author contributions}

Ji Young Kang: conception and/or design of the study, collection of the data, preparation or critical revision of the manuscript, approval of the final version of the manuscript. Sook Young Lee: conception and/or design of the study, analysis and interpretation of the data, preparation or critical revision of the manuscript, approval of the final version of the manuscript.

Chin Kook Rhee: collection of the data, analysis and interpretation of the data, preparation or critical revision of the manuscript, approval of the final version of the manuscript Seung Joon Kim: conception and/or design of the study, analysis and interpretation of the data, preparation or critical revision of the manuscript, approval of the final version of the manuscript.

Soon Seog Kwon: conception and/or design of the study, analysis and interpretation of the data, preparation or critical revision of the manuscript, approval of the final version of the manuscript.

Young Kyoon Kim: collection of the data, analysis and interpretation of the data, preparation or critical revision of the manuscript, approval of the final version of the manuscript.

\section{Disclosure}

The authors report no conflicts of interest in this work.

\section{References}

1. Vignola AM, Scichilone N, Bousquet J, Bonsignore G, Bellia V. Aging and asthma: pathophysiological mechanisms. Allergy. 2003;58(3): 165-175.

2. Ide K, Hayakawa H, Yagi T, et al. Decreased expression of Th2 type cytokine mRNA contributes to the lack of allergic bronchial inflammation in aged rats. J Immunol. 1999;163(1):396-402.

3. Gelfand EW, Joetham A, Cui ZH, et al. Induction and maintenance of airway responsiveness to allergen challenge are determined at the age of initial sensitization. J Immunol. 2004;173(2):1298-1306.

4. Hasegawa A, Miki T, Hosokawa H, et al. Impaired GATA3-dependent chromatin remodeling and $\mathrm{Th} 2$ cell differentiation leading to attenuated allergic airway inflammation in aging mice. J Immunol. 2006;176(4): 2546-2554.

5. Busse PJ, Zhang TF, Srivastava K, Schofield B, Li XM. Effect of ageing on pulmonary inflammation, airway hyperresponsiveness and $\mathrm{T}$ and $\mathrm{B}$ cell responses in antigen-sensitized and -challenged mice. Clin Exp Allergy. 2007;37(9):1392-1403. 
6. Carnieli DS, Yoshioka E, Silva LF, et al. Inflammation and remodeling in infantile, juvenile, and adult allergic sensitized mice. Pediatr Pulmonol. 2011;46(7):650-665.

7. Hanania NA, King MJ, Braman SS, et al. Asthma in Elderly workshop participants. Asthma in the elderly: Current understanding and future research needs-a report of a National Institute on Aging (NIA) workshop. J Allergy Clin Immunol. 2011;128(Suppl 3):S4-S24.

8. Illi S, von Mutius E, Lau S, et al. Perennial allergen sensitisation early in life and chronic asthma in children: a birth cohort study. Lancet. 2006;368(9537):763-770.

9. Gosens R, Zaagsma J, Meurs H, Halayko AJ. Muscarinic receptor signaling in the pathophysiology of asthma and COPD. Respir Res. 2006;7:73

10. Gwilt CR, Donnelly LE, Rogers DF. The non-neuronal cholinergic system in the airways: an unappreciated regulatory role in pulmonary inflammation? Pharmacol Ther. 2007;115(2):208-222.

11. Ohta S, Oda N, Yokoe T, et al. Effect of tiotropium bromide on airway inflammation and remodelling in a mouse model of asthma. Clin Exp Allergy. 2010;40(8):1266-1275.

12. Kang JY, Rhee CK, Kim JS, et al. Effect of tiotropium bromide on airway remodeling in a chronic asthma model. Ann Allergy Asthma Immunol. 2012;109(1):29-35.

13. Restrepo RD. Use of inhaled anticholinergic agents in obstructive airway disease. Respir Care. 2007;52(7):833-851.

14. Vincken W, van Noord JA, Greefhorst AP, et al. Improved health outcomes in patients with COPD during 1 yr's treatment with tiotropium. Eur Respir J. 2002;19(2):209-216.

15. Anzueto A, Tashkin D, Menjoge S, Kesten S. One-year analysis of longitudinal changes in spirometry in patients with COPD receiving tiotropium. Pulm Pharmacol Ther. 2005;18(2):75-81.

16. Kerstjens HA, Engel M, Dahl R, et al. Tiotropium in asthma poorly controlled with standard combination therapy. $N$ Engl J Med. 2012 367(13):1198-1207.

17. Kerstjens HA, Disse B, Schroder-Babo W, et al. Tiotropium improves lung function in patients with severe uncontrolled asthma: a randomized controlled trial. J Allergy Clin Immunol. 2011;128(2):308-314.

18. Nam HS, Lee SY, Kim SJ, et al. The soluble tumor necrosis factor-alpha receptor suppresses airway inflammation in a murine model of acute asthma. Yonsei Med J. 2009;50(4):569-575.

19. Myou S, Leff AR, Myo S, et al. Blockade of inflammation and airway hyperresponsiveness in immune-sensitized mice by dominantnegative phosphoinositide 3-kinase-TAT. J Exp Med. 2003;198(10): 1573-1582.

20. Padrid P, Snook S, Finucane T, et al. Persistent airway hyperresponsiveness and histologic alterations after chronic antigen challenge in cats. Am J Respir Crit Care Med. 1995;151(1):184-193.
21. Busse PJ, Schofield B, Birmingham N, et al. The traditional Chinese herbal formula ASHMI inhibits allergic lung inflammation in antigensensitized and antigen-challenged aged mice. Ann Allergy Asthma Immunol. 2010;104(3):236-246.

22. Kita H. Eosinophils: multifunctional and distinctive properties. Int Arch Allergy Immunol. 2013;161 Suppl 2:3-9. doi: 10.1159/ 000350662. Epub May 29, 2013.

23. Coleman JM, Naik C, Holguin F, et al. Epithelial eotaxin-2 and eotaxin-3 expression: relation to asthma severity, luminal eosinophilia and age at onset. Thorax. 2012;67(12):1061-1066.

24. Chakir J, Shannon J, Molet S, et al. Airway remodeling-associated mediators in moderate to severe asthma: effect of steroids on TGF-beta, IL-11, IL-17, and type I and type III collagen expression. J Allergy Clin Immunol. 2003;111(6):1293-1298.

25. Agache I, Ciobanu C, Agache C, Anghel M. Increased serum IL-17 is an independent risk factor for severe asthma. Respir Med. 2010;104(8): 1131-1137.

26. Silverpil E, Lindén A. IL-17 in human asthma. Expert Rev Respir Med. 2012;6(2):173-186.

27. Alvarez-Rodríguez L, López-Hoyos M, Muñoz-Cacho P, MartínezTaboada VM. Aging is associated with circulating cytokine dysregulation. Cell Immunol. 2012;273(2):124-132.

28. Bousquet J, Jeffery PK, Busse WW, Johnson M, Vignola AM. Asthma. From bronchoconstriction to airways inflammation and remodeling. Am J Respir Crit Care Med. 2000;161(5):1720-1745.

29. Boulet LP, Sterk PJ. Airway remodelling: the future. Eur Respir J. 2007;30(5):831-834.

30. Kistemaker LE, Oenema TA, Meurs H, Gosens R. Regulation of airway inflammation and remodeling by muscarinic receptors: Perspectives on anticholinergic therapy in asthma and COPD. Life Sci. 2012;91(21-22):1126-1133.

31. Meurs H, Dekkers BG, Maarsingh H, Halayko AJ, Zaagsma J, Gosens R. Muscarinic receptors on airway mesenchymal cells: Novel findings for an ancient target. Pulm Pharmacol Ther. 2013;26(1): $145-155$.

32. Grainge CL, Lau LC, Ward JA, et al. Effect of bronchoconstriction on airway remodeling in asthma. $N$ Engl J Med. 2011;364(21): 2006-2015.

33. Lee HK, Lim MY, Bok SM, et al. Age differences in cholinergic airway responsiveness in relation with muscarinic receptor subtypes. Life Sci. 2007;81(3):204-209.

34. Wright DB, Trian T, Siddiqui S, et al. Phenotype modulation of airway smooth muscle in asthma. Pulm Pharmacol Ther. 2013;26(1):42-49.

35. Ladislas R. Cellular and molecular mechanisms of aging and age related diseases. Pathol Oncol Res. 2000;6(1):3-9.
Clinical Interventions in Aging

\section{Publish your work in this journal}

Clinical Interventions in Aging is an international, peer-reviewed journal focusing on evidence-based reports on the value or lack thereof of treatments intended to prevent or delay the onset of maladaptive correlates of aging in human beings. This journal is indexed on PubMed Central, MedLine, the American Chemical Society's 'Chemical Abstracts Ser-

\section{Dovepress}

vice' (CAS), Scopus and the Elsevier Bibliographic databases. The manuscript management system is completely online and includes a very quick and fair peer-review system, which is all easy to use. Visit http://www.dovepress.com/testimonials.php to read real quotes from published authors. 